\title{
Therapeutic Activity of Partially Purified Fractions of Emblica officinalis (Syn. Phyllanthus emblica) Dried Fruits against Trypanosoma evansi
}

\author{
Shaba Peter ${ }^{1}$, Sahab Dey ${ }^{1}$, Bhanuprakash Veerakyathappa ${ }^{2}$, Singh Raj Kumar ${ }^{2}$ and Chaudary Paulad ${ }^{3}$ \\ 1. Division of Medicine, Indian Veterinary Research Institute, Izatnagar, Uttar Pradesh 243 122, India \\ 2. Indian Veterinary Research Institute, Regional Station, Mukteswar, Uttranchal 263 138, India \\ 3. Division of Bacteriology and Biotechnology, Indian Veterinary Research Institute, Izatnagar, Uttar Pradesh 243 122, India
}

\begin{abstract}
Emblica officinalis (E. officinalis) dried fruits were evaluated for its antitrypanosomal activity and cytotoxic effects. Vero cell line maintained in DMEM (Dubecco's Modified Eagle Medium) and incubated with Trypanosoma evansi for more than $12 \mathrm{~h}$. MPE was added to the Vero cell culture medium at different concentrations $(250 \sim 1,000 \mu \mathrm{g} / \mathrm{mL})$ with trypanosomes concentration $\left(1 \times 10^{6}\right.$ trypanosomes $/ \mathrm{mL}$ in each ELISA plate well) and incubated at appropriate conditions for $72 \mathrm{~h}$. In-vitro cytotoxicity of MPE of $E$. officinalis was determined on Vero cells at concentrations $((1.56 \sim 100 \mu \mathrm{g} / \mathrm{mL})$. Acute toxicity and in-vivo infectivity tests were done in mice. Obtained MPE of E. officinalis underwent process of purification via column chromatography, preparative chromatography and HPLC (higher performance liquid chromatography) with bioassay at different strata on Alsever's medium. In-vivo assay for trypanocidal activity, MPE and PPFs (partially purified fractions) of E. officinalis with two sets of mice, each mouse was inoculated with $1 \times 10^{4} / \mathrm{mL}$ of trypanosomes and treated (48 h post inoculation) at concentrations $(12.5,25,50,100 \mathrm{and} 200 \mathrm{mg} / \mathrm{kg}$ body weight) were administered at dose rate of $100 \mu \mathrm{L}$ per mouse via intraperitoneal route (in treating parassitemic mice) to different groups of mice, 6 mice per concentration. HPLC of partially purified fractions of $E$. officinalis was carried out with mobile phase of acetonitrile: water (40:60) in gradient mode. In vitro, MPE induced immobilization and killing of the parasites in concentration-time dependent manner. Significant reduction of trypanosomes counts from concentration of $250 \mu \mathrm{g} / \mathrm{mL}$ and complete killing of trypanosomes at 5 th hour of observation, which was statistically equivalent to 4th hour of Diminazine Aceturate (Berenil), standard reference drug used. HPLC of the partially purified fractions revealed two major prominent peaks at retention time of $1 \sim 4$ min. In vivo, both MPE and PPFs of test material did prolong lives of mice by 6 9 days but could not cure them. At concentration of $2,000 \mathrm{~kg} / \mathrm{kg}$ body weight of MPE in acute test, all mice survived. For in-vivo infectivity test, mice injected with immobilized trypanosomes developed parasitemia and died while, the other group survived. MPE, PPFs and Diminazine Aceturate were toxic to Vero cells at all concentrations exception of 1.56, $1.56 \sim 3.13$ and $1.56 \sim 6.25 \mu \mathrm{g} / \mathrm{mL}$, respectively. From this report, PPFs of E. officinalis dried fruits demonstrated potential pathway for a new development of trypanocide in near future if additional investigations are put in place.
\end{abstract}

Key words: Emblica officinalis dried fruits, in vitro and in vivo partially purified fractions trypanocidal activity, Trypanosoma evansi, in vitro cytotoxicity.

\section{Introduction}

Trypanosomosis, a disease caused by blood protozoan parasites of genus Trypanosoma, is on the increase in endemic regions, (e.g., Africa and Latin America), where millions of population and cattle are

Corresponding author: Shaba Peter, Ph.D., chief lecturer, research fields: alternative medicine-major, animal health related diseases and basic anatomical structures of domestic animals. affected with considerable morbidity and mortality, which are due to largely emergence of resistant strains of trypanosomes, vectors reaching new heights of highlands and occupying vast lands that are now uncultivable, and in addition to resistant to available trypanocides in endemic areas of the world where trypanosomosis thrives for decades $[1,2]$. It is an important parasitic disease of veterinary and medical sciences $[2,3]$. The disease is caused by distinct agents, 
such as Trypanosoma evansi in animals as to Trypanosoma brucei rhodesiense in humans [2]. Human African trypanosomosis, for instance, affects more than 60 million people with 300,000 500,000 new cases per annum [4-6]. About 3 billion pounds are lost annually in Africa from animal trypanosomosis [7].

Reports of resistance to available trypanocides [8] and by trypanosomes [1,2] had hampered effective treatment and control.

Reports of naturally active extras/fractions/compounds from medicinal plants against trypanosomes have been reported [9-14].

In folk medicine, Emblica officinalis (E. officinalis) dried fruits (Syn. Phyllanthus emblica) (Euphorbiaceae) has been used as anti-inflammatory, anti-stomach ache, antipyretic, and in disease conditions, such as anemia, jaundice, dyspepsin, scabies and itch, nausea and emesis have been documented $[15,16]$.

Phytochemical compounds, such as triterpene [17] phyllantine, zeatin nucleotide and riboside [18]; Kaempherol-3-0-B-D, quercentin-3-0-B-D and glucose [19] and deterpene [20] have been isolated from E. officinalis dried fruits. Also, it includes tannins, alkaloids, polyphenols, vitamins and minerals, gallic acid, ellagic acid, Emblicanin A \& B, phyllembein, quercetin and ascorbic acid [21, 22].

Previously, preliminary report of anti-trypanosomal activity of $E$. officinalis dried fruits has been reported [23].

In this report, Emblica officinalis dried fruits were extracted with methanol, obtained MPE (methanolic plant extract) was further fractionated via column chromatography, preparative chromatography and its level of purification was determined by HPLC (high performance liquid chromatography) with attended bioassay at different strata with interest on in-vivo trypanocidal activity.

\section{Material and Methods}

\subsection{Plant Material}

Emblica officinalis dried fruits of the family euphorbiaceae were obtained from reputable Ayurvedic shop from hilly region of Palampur, Himachal Pradesh. Plant material was identified by Institute of Himalaya Biosource Technology, Palampur, Himachal Pradesh, India.

\subsection{Extraction}

Twenty grammes of E. officinalis dried fruits were pounded into powder with pestle and mortar and cold extracted twice with $200 \mathrm{~mL}$ of methanol (analytical grade) according to Stahl [24]. The filtrates were dried at $37^{\circ} \mathrm{C}$ and stored at $4{ }^{\circ} \mathrm{C}$ until used.

\subsection{TLC (Thin Layer Chromatography) Plates}

Aliquots $(0.2 \mathrm{~mL})$ of MPE and partial purified fractions of $E$. officinalis dried fruits were applied on TLC plates, which were dried under room temperature and immersed inside the solvent systems in glass jar listed in the next subsection. This was done to detect, if any, the presence of bioactive constituents in applied MPE and PPFs (partially purified fractions). After full development of plates in solvent systems, plates were dried at room temperature. Then, one set of TLC plates were immersed in iodine vapours in a glass jar. Second set of TLC plates were sprayed with Vanillin-sulphuric acid spray. Both media used facilitated the detection of bioactive constituents. This was carried out according to the method of Stahl [24].

\subsection{Applied Solvent Systems}

The following solvent systems were tested to develop the TLC plates to obtain a more suitable system for both extract and fractions according to the method of Stahl [24]:

- Chloroform/hexane/acetic acid (50:50:1);

- Chloroform/ethyl acetate/acetic acid (50:50:1);

- Methanol and chloroform (20: 80).

\subsection{Test Organism}

Trypanosoma evansi was obtained from the Division of Parasitology, IVRI (Indian Veterinary Research 
Institute), Izatnagar and was maintained in the laboratory by serial sub-passage in Swiss albino mice. The strain was routinely tested for virulence following the method of Williamson et al. [25].

\subsection{In-vitro Tryponocidal Activity}

In-vitro trypanocidal activity was carried out on two media:

(1) On modified method of Oliveira et al. [26]: In this method, a Vero cell line was grown in DMEM (Dulbecco's Modified Eagle Medium) (Sigma) in 96-well flat bottom micro culture plates (Nunc, Denmark). Each well received $100 \mu \mathrm{L}$ of DMEM containing $5 \times 10^{5}$ cells $/ \mathrm{mL}$. The plates were incubated at $37{ }^{\circ} \mathrm{C}$ under $5 \% \quad \mathrm{CO}_{2}$ for $48 \mathrm{~h}$ to complete development of monolayer. After the formation of confluent monolayer, the medium (DMEM) was discarded and replaced with a fresh DMEM. And the medium was supplemented with $20 \sim 40 \%$ FCS (fetal calf serum), Gibco USA and antibiotics (100 units penicillin, $100 \mu \mathrm{g}$ streptomycin and $40 \mu \mathrm{g}$ gentamycin). A high parasitemic blood from mouse was diluted with DMEM to obtain a final parasite of $1 \times 10^{6}$ parasites $/ \mathrm{mL}$. The suspension $(100 \mathrm{~mL}$ of medium with trypanosomes was added at rate of 1:1 to MPE of $E$. officinalis dried fruits at concentrations $(250 \sim 1,000$ $\mu \mathrm{g} / \mathrm{mL})$. The suspension (100 $\mathrm{mL}$ of medium with trypanosomes) was added at rate of $1: 1$ to test extract and the plates were incubated at $37{ }^{\circ} \mathrm{C}$ under $5 \% \mathrm{CO}_{2}$. The mixture was incubated for $9 \mathrm{~h}$. The test was repeated at least thrice and the plate was incubated under the same conditions mentioned above. The test was repeated at least thrice.

Stock of test MPE was solubilized in 1\% DMSO (dimethyl suphoxide);

(2) On Alsever's medium: Trypanosomes were suspended in Alsever's solution with inactivated bovine serum at $58{ }^{\circ} \mathrm{C}$ for $1 \mathrm{~h}$. Trypanosomes concentration was $1 \times 10^{6}$ parasites $/ \mathrm{mL}$. $180 \mu \mathrm{L}$ of the medium was added to the test extract of E. officinalis dried fruits $(20 \mu \mathrm{L})$ and incubated at $37{ }^{\circ} \mathrm{C}$ with $5 \%$ carbon dioxide for $5 \mathrm{~h}$. On hourly basis, drops of the incubated mixture were observed under inverted microscope for antitrypanosomal activity [27].

The concentration of DMSO in the experiment had no deleterious effect by itself on host cells or parasites. $1 \%$ DMSO in distilled water was used as control [28].

\subsection{In-vivo Infectivity Assessment}

In-vivo infectivity of MPE of E. officinalis dried fruits was carried out after successful completion of anti-trypanosomal activity. Contents of microculture plate wells that contained reduced and apparently killed trypanosomes with MPE of the test material were inoculated $(0.1 \mathrm{~mL}$ per mouse $)$ into two groups of mice (six per group) via intra-peritoneal, and observed for more than 60 days for parasitaemia [29, 30].

\subsection{In-vitro Cytotoxicity Test}

Cytotoxic effects of the MPE and pooled PPFs of $E$. officinalis dried fruits were determined according to the method described by Sidwell and Hoffman [31]. Vero cell line was grown in DMEM (Dulbecco's Modified Eagle Medium) (Sigma) Gibco, USA antibiotics (100 units penicillin, $100 \mu \mathrm{g}$ streptomycin and $40 \mu \mathrm{g}$ gentamycin) in 96-well flat bottom micro culture plates (Nunc, Denmark). Each well received $100 \mu \mathrm{L}$ of DMEM containing $5 \times 10^{5}$ cells $/ \mathrm{mL}$. The plates were incubated at $37^{\circ} \mathrm{C}$ under $5 \% \mathrm{CO}_{2}$ for $48 \mathrm{~h}$. After the formation of confluent monolayer, the medium was discarded and replaced with a fresh one. A high parasitaemic blood from mouse was diluted with DMEM to obtain a final parasite of $1 \times 10^{6}$ parasites $/ \mathrm{mL}$. Confluent monolayers of Vero cells were treated with serial dilutions of MPE and pooled PPFs of the test material at concentrations $(1.56 \sim 100 \mu \mathrm{g} / \mathrm{mL})$ in triplicate and incubated under the same conditions described previously. After $24 \mathrm{~h}$ of incubation, the culture plates were observed for evidence of cytotoxic effects. The plates were incubated for $72 \mathrm{~h}$ and observed daily. It was repeated thrice. In each case, after the $72 \mathrm{~h}$ of incubation, the culture media of the 
incubated Vero cells were discarded. The adhered cells to ELISA plates were stained with a drop of crystal violet in phosphate buffered solution. The plates were incubated for $24 \mathrm{~h}$ at $37{ }^{\circ} \mathrm{C}$ in an ordinary incubator. After $24 \mathrm{~h}$ of incubation, the culture plates were observed for evidence of cytotoxic effects.

\subsection{Acute Toxicity Test}

Acute toxicity test of $E$. officinalis dried fruits was carried out according to the method of Madubunyi [32]. In this method, powdered test material was dissolved in either distilled water or vegetable oil pending on it solubility at a dose rate of $2,000 \mathrm{mg} / \mathrm{kg}$ body weight and administered to six mice according to the body weight. Mice were observed for at least two weeks for any sign of toxicity and mortality.

\subsection{Column Chromatography of Methanolic Plant} Extract of E. officinalis Dried Fruits

This was done according to the method of Stahl [24]. Obtained MPE of E. officinalis dried fruits were used for bioassay-guided purification. Residues (11.623 $\mathrm{g}$ of MPE) obtained from methanol extraction of $60 \mathrm{~g} E$. officinalis dried fruits were used for column chromatography. Extract was loaded into already packed glass column with silica gel (60 120 mesh) for column chromatography. The extract was eluted with varied ratios of chloroform/methanol.

\subsection{In-vivo Trypanocidal Activity of Methanolic Plant} Extract and Partially Purified Fractions of E. officinalis Dried Fruits

This was carried out as per the method of Freiburghaus et al. [9]. Six mice in a group were inoculated with trypanosomes $\left(1 \times 10^{4} / \mathrm{mL}\right)$. Infected mice were treated with both MPE and pooled PPFs of $E$. officinalis dried fruits at concentrations (12.5 200 mg/kg body weight) intraperitoneally $48 \mathrm{~h}$ post on set of parasitemia. $1 \%$ of DMSO was added to the extract, PPFs and diluted with DMEM. A drop of blood was taken from the tail-end of the mice daily and parasites were counted as previously described.

2.12 HPLC (Higher Performance Liquid Chromatography) Analysis of Representative Pooled Partially Purified Fractions from E. officinalis Dried Fruits

HPLC analysis was done according to Sharma et al. [33]. HPLC (Waters) analysis by injecting $20 \mu \mathrm{L}$ of dissolved representative fractions of $E$. officinalis in HPLC graded methanol via 18 columns. Gradient of methanol: water $(40: 60)$ to methanol $(100 \%)$ for 30 min was used. At a zero minute, the ration of acetonitrile to water percentages was 10:90. But at $25 \mathrm{~min}$, the ratio percentages were $64: 36$, respectively.

2.13 Institute Committee on Welfare and Cruelty to Animals

Indian Veterinary Research Institute Committee on Welfare and Cruelty to Animals received and approved application for the usage of mice in this research.

\subsection{Statistical Analysis}

Results of trypanocidal activity were expressed as "mean \pm SEM". Statistical significance was determined by Sigma Stat (Jandel), USA.

\section{Results}

In this current research, results are presented in Tables 1-9 and Figs. 1-3 accordingly.

\subsection{Extraction}

Solvent, methanol, was used in extraction of $E$. officinalis dried powdered fruits. It appeared that methanol was suitable for its extraction as per the bioactive constituents present in the MPE of sample material observed on the TLC plates.

\subsection{Solvent System}

Out of four solvent systems tested in the analysis of TLC plates with applied aliquots of MPE and fractions of the test material, solvent systems, 
methanol/chloroform (20:80) and chloroform/ethyl acetate/acetic acid (50:50:1), were suitable than other solvent systems tested (plates not shown) for both in that order. On the TLC plates, different patterns of bioactive constituents were on display from MPE and pooled fractions of sample material, which were subsequently responsible for anti-trypanosomal activity.

\subsection{In-vivo Infectivity Test}

One group of mice inoculated with contents of ELISA plate wells with completely killed trypanosomes survived for more than 60 days as to the other group inoculated with contents of ELISA plate wells with reduced trypanosomes count that died of parasitemia.

\subsection{In-vitro Trypanocidal Activity of Methanolic Plant} Extract of E. officinalis Dried Fruits

Results of in-vitro trypanocidal activity of MPE of $E$. officinalis dried fruits at different concentrations $(250 \sim 1,000 \mu \mathrm{g} / \mathrm{mL})$ were as given in Fig. 1. In this result, strong trypanocidal activity was observed with complete killing of the trypanosomes at $5 \mathrm{~h}$ of incubation at $250 \mu \mathrm{g} / \mathrm{mL}$, which was statistically the same as Diminazine Aceturate $(50 \mu \mathrm{g} / \mathrm{mL})$ standard drug at $4 \mathrm{~h}$ of incubation (Fig. 1). Trypanocidal activity was concentration-time dependent faction. Average mean trypanosomes counts from $37.67 \pm 0.58$ and below is significant between the treatment groups and negative control $(P \leq 0.05$ to 0.01$)$.

\subsection{In-vitro Cytotoxicity Test}

As shown in Tables 1 and 2, MPE and PPFs of $E$. officinalis dried fruits, and Diminazine Aceturate were cytotoxic to Vero cells in all concentrations except at $1.56,1.56 \sim 3.13$ and $1.56 \sim 6.25 \mu \mathrm{g} / \mathrm{mL}$, respectively. Cytotoxic effects, such as distortion, sloughing, swelling and dead of the affected cells, were observed compared to normal cells.

\subsection{Acute Toxicity Test}

At concentration of $2,000 \mathrm{~kg} / \mathrm{kg}$ body weight, MPE of E. officinalis was not toxic to mice in different groups. All mice survived in acute toxicity test as given in Table 3.

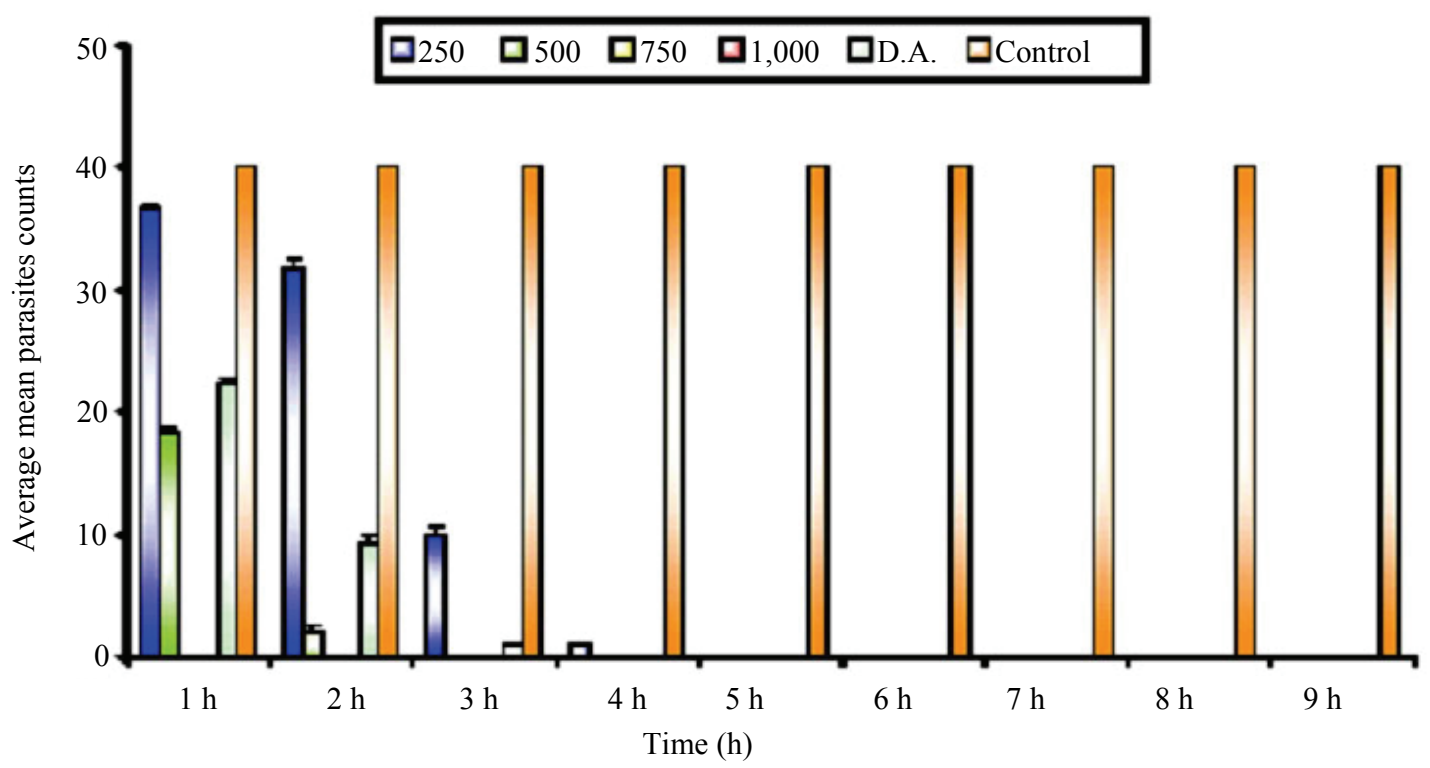

Fig. 1 In-vitro trypanocidal activity of methanolic extract of $E$. officinalis on Vero cell line.

Test extract: concentrations $(250 \sim 1,000 \mu \mathrm{g} / \mathrm{mL})$;

DA: Diminazine Aceturate $(50 \mu \mathrm{g} / \mathrm{mL})$.

Control: parasites + medium;

$P$ value: $P \leq 0.05$ to 0.01 . 
Table 1 Cytotoxic effect of methanolic plant extract of $E$. officinalis dried fruits on Vero cell line compared to Diminazine Aceturate (Berenil).

\begin{tabular}{|c|c|c|c|c|c|c|c|}
\hline \multirow{3}{*}{$\begin{array}{l}\text { Concentration of test } \\
\text { material }(\mu \mathrm{g} / \mathrm{mL})\end{array}$} & \multicolumn{6}{|c|}{ Effects of test extract at various periods of incubation } & \multirow{3}{*}{ Control } \\
\hline & \multicolumn{2}{|l|}{$24 \mathrm{~h}$} & \multicolumn{2}{|c|}{$48 \mathrm{~h}$} & \multicolumn{2}{|l|}{$72 \mathrm{~h}$} & \\
\hline & Emblica officinalis & Berenil & Emblica officinalis & Berenil & Emblica officinalis & Berenil & \\
\hline 100 & $100 \%$ & $66.6 \%$ & $100 \%$ & $100 \%$ & $100 \%$ & $100 \%$ & 0 \\
\hline 50 & $100 \%$ & $33.3 \%$ & $100 \%$ & $100 \%$ & $100 \%$ & $100 \%$ & 0 \\
\hline 25 & $100 \%$ & 0 & $100 \%$ & $100 \%$ & $100 \%$ & $100 \%$ & 0 \\
\hline 12.5 & $100 \%$ & 0 & $100 \%$ & 0 & $100 \%$ & $33.3 \%$ & 0 \\
\hline 6.25 & 0 & 0 & $100 \%$ & 0 & $66.6 \%$ & 0 & 0 \\
\hline 3.13 & 0 & 0 & 0 & 0 & $33.3 \%$ & 0 & 0 \\
\hline 1.56 & 0 & 0 & 0 & 0 & 0 & 0 & 0 \\
\hline
\end{tabular}

MPE of E. officinalis and Diminazine Aceturate were toxic to Vero cell line except at concentrations of $1.56 \mathrm{and} 6.25 \sim 1.56 \mu \mathrm{g} / \mathrm{mL}$; Same concentrations were used for Diminazine Aceturate and Berenil.

Table 2 Cytotoxic effect of representative pooled partially purified fractions of $E$. officinalis dried fruits on Vero cell line compared to Diminazine Aceturate (Berenil).

\begin{tabular}{|c|c|c|c|c|c|c|c|}
\hline \multirow{3}{*}{$\begin{array}{l}\text { Concentration of test } \\
\text { material }(\mu \mathrm{g} / \mathrm{mL})\end{array}$} & \multicolumn{6}{|c|}{ Effects of test extract at various periods of incubation } & \multirow{3}{*}{ Control } \\
\hline & \multicolumn{2}{|l|}{$24 \mathrm{~h}$} & \multicolumn{2}{|c|}{$48 \mathrm{~h}$} & \multicolumn{2}{|l|}{$72 \mathrm{~h}$} & \\
\hline & Emblica officinalis & Berenil & Emblica officinalis & Berenil & Emblica officinalis & Berenil & \\
\hline 100 & $100 \%$ & $66.6 \%$ & $100 \%$ & $100 \%$ & $100 \%$ & $100 \%$ & 0 \\
\hline 50 & $100 \%$ & $33.3 \%$ & $100 \%$ & $100 \%$ & $100 \%$ & $100 \%$ & 0 \\
\hline 25 & $100 \%$ & 0 & $100 \%$ & $100 \%$ & $100 \%$ & $100 \%$ & 0 \\
\hline 12.5 & $100 \%$ & 0 & $100 \%$ & 0 & $100 \%$ & $33.3 \%$ & 0 \\
\hline 6.25 & 0 & 0 & $33.3 \%$ & 0 & $66.6 \%$ & 0 & 0 \\
\hline 3.13 & 0 & 0 & 0 & 0 & 0 & 0 & 0 \\
\hline 1.56 & 0 & 0 & 0 & 0 & 0 & 0 & 0 \\
\hline
\end{tabular}

PPFs of E. officinalis and diminazine aceturate were toxic to Vero cell line except at concentrations of 1.56 and $6.25 \sim 1.56 \mu \mathrm{g} / \mathrm{mL}$; Same concentrations were used for diminazine aceturate (Berenil).

Table 3 Acute toxicity test of methanolic extract of $E$. officinali dried fruits in mice.

\begin{tabular}{|c|c|c|c|c|}
\hline $\begin{array}{l}\text { Number of mice per } \\
\text { extract }\end{array}$ & $\begin{array}{l}\text { Body weight of } \\
\text { mice }(\mathrm{g})\end{array}$ & Type of plant extract & $\begin{array}{l}\text { Concentration used } \\
(2,000 \mathrm{mg} / \mathrm{kg} \text { body weight })\end{array}$ & $\begin{array}{l}\text { Observation (toxicity signs and } \\
\text { mortality) }\end{array}$ \\
\hline 1 & 27 & \multirow{6}{*}{ Emblica officinalis } & $0.27 \mathrm{~mL}$ & $\begin{array}{l}\text { The mice Survived without any } \\
\text { apparent toxic signs observed }\end{array}$ \\
\hline 2 & 28 & & $0.28 \mathrm{~mL}$ & - \\
\hline 3 & 29 & & $0.29 \mathrm{~mL}$ & - \\
\hline 4 & 26 & & $0.26 \mathrm{~mL}$ & - \\
\hline 5 & 28 & & $0.28 \mathrm{~mL}$ & - \\
\hline 6 & 27 & & $0.27 \mathrm{~mL}$ & - \\
\hline
\end{tabular}

\subsection{Column Chromatography of Methanolic Plant}

Extract of E. officinalis Dried Fruits with Corresponding Trypanocidal Activity

Elution of MPE of E. officinalis dried fruits with ratios of chloroform/methanol yielded 581 fractions of $25 \mathrm{~mL}$ each. Solvent systems, chloroform/hexane/acetic acid (50:50:1) and chloroform/ethyl acetate/acetic acid (50:50:1), were used to analyzed the TLC plates. However, chloroform/ethyl acetate/acetic acid (50:50:1) was more suitable for resolutions of the TLC plates. Subsequently, TLC plates were detected in iodine vapors. Pooling of fractions was done according to similarity of TLC profiles and were given as follows: (1) Pooled Fractions I (1 7 and 11 40); (2) Pooled Fractions II (8 10); (3) Pooled Fractions III (41 96); (4) Pooled Fractions IV (97 581). 
Fractions I (1 7 and 11 40) did depict presence of small amount of bioactive components and were combined as a result of similarity of TLC profile. Fractions II $(8 \sim 10)$ displayed three layers of broad bands on TLC plates and nothing remained at the origin of applications. In Fractions III (41 96), there was a little mobility of bioactive components from the origin of applications. But, Fractions IV (97 581) mostly did not move from origin of applications of aliquots as depicted on TLC plates, which gradually increased in intensity. Corresponding in-vitro trypanocidal activities were given in Tables 4-7.

\subsection{In-vitro Trypanocidal Activity of PPFs (Partially} Purified Fractions) of E. officinalis Dried Fruits

As shown in Table 8, distinct pooled fractions

Table 4 Pooled Fractions I (1 7 and 11 40).

\begin{tabular}{llllll}
\hline $\begin{array}{l}\text { Concentration of pooled plant } \\
\text { extract }(\mu \mathrm{g} / \mathrm{mL})\end{array}$ & $1 \mathrm{~h}$ & $2 \mathrm{~h}$ & $3 \mathrm{~h}$ & $4 \mathrm{~h}$ & $5 \mathrm{~h}$ \\
\hline 250 & $40.00 \pm 0.0$ & $40.00 \pm 0.0$ & $31.33 \pm 0.33$ & $23.67 \pm 0.68$ & $12.67 \pm 0.68$ \\
500 & $40.00 \pm 0.0$ & $40.00 \pm 0.0$ & $28.67 \pm 0.33$ & $18.67 \pm 0.33$ & $8.667 \pm 0.68$ \\
750 & $40.00 \pm 0.0$ & $40.00 \pm 0.0$ & $18.67 \pm 0.33$ & $9.667 \pm 0.33$ & $3.667 \pm 0.33$ \\
1000 & $34.67 \pm 0.33$ & $20.67 \pm 0.68$ & $11.33 \pm 0.33$ & $0.0 \pm 0.0$ & $0.0 \pm 0.0$ \\
$\begin{array}{l}\text { Diminazine Aceturate (50) } \\
\text { (positive control) }\end{array}$ & $22.33 \pm 0.33$ & $9.000 \pm 0.58$ & $1.333 \pm 0.33$ & $0.0 \pm 0.0$ & $0.0 \pm 0.0$ \\
Control (negative control) & $40.00 \pm 0.0$ & $40.00 \pm 0.0$ & $40.00 \pm 0.0$ & $40.00 \pm 0.0$ & $40.00 \pm 0.0$ \\
\hline
\end{tabular}

Bioassay status: Significant reduction of parasites counts started from concentration of $250 \mu \mathrm{g} / \mathrm{mL}$ and complete killing of parasites at $1,000 \mu \mathrm{g} / \mathrm{mL}$ at 4 th hour of incubation. An average mean parasites count of $37.67 \pm 0.58$ is statistically critical value. Average mean from $37.67 \pm 0.58$ and below is significant between the treatment groups and negative control $(P \leq 0.05$ to 0.01$)$.

Table 5 Pooled Fractions II (8 10).

\begin{tabular}{llllll}
\hline $\begin{array}{l}\text { Concentration of pooled plant } \\
\text { extract }(\mu \mathrm{g} / \mathrm{mL})\end{array}$ & $1 \mathrm{~h}$ & $2 \mathrm{~h}$ & $3 \mathrm{~h}$ & $4 \mathrm{~h}$ & $5 \mathrm{~h}$ \\
\hline 250 & $40.00 \pm 0.0$ & $22.67 \pm 0.68$ & $10.67 \pm 0.68$ & $5.667 \pm 0.33$ & $25.00 \pm 0.25$ \\
500 & $40.00 \pm 0.0$ & $19.67 \pm 0.33$ & $8.667 \pm 0.33$ & $4.667 \pm 0.33$ & $0.0 \pm 0.0$ \\
750 & $40.00 \pm 0.0$ & $16.33 \pm 0.33$ & $7.333 \pm 0.33$ & $0.0 \pm 0.0$ & $0.0 \pm 0.0$ \\
1000 & $33.67 \pm 0.33$ & $14.67 \pm 0.33$ & $0.0 \pm 0.00$ & $0.0 \pm 0.0$ & $0.0 \pm 0.0$ \\
Diminazine Aceturate (50) & $22.33 \pm 0.33$ & $9.000 \pm 0.58$ & $1.333 \pm 0.33$ & $0.0 \pm 0.0$ & $0.0 \pm 0.0$ \\
Positive control & $40.00 \pm 0.0$ & $40.00 \pm 0.0$ & $40.00 \pm 0.0$ & $40.00 \pm 0.0$ & $40.00 \pm 0.0$ \\
Control (Negative control) & &
\end{tabular}

Bioassay status: Significant reduction of parasites counts started from concentration $250 \mu \mathrm{g} / \mathrm{mL}$ and complete killing of parasites at $500 \mu \mathrm{g} / \mathrm{mL}$ at 5 th hour of observation. An average mean parasites count of $37.67 \pm 0.58$ is statistically critical value. Average meanparasites counts from $37.67 \pm 0.58$ and below is significant between the treatment groups and negative control $(P \leq 0.05$ to 0.01$)$.

Table 6 Pooled Fractions III (41 96).

\begin{tabular}{llllll}
\hline $\begin{array}{l}\text { Concentration of pooled plant } \\
\text { extract }(\mu \mathrm{g} / \mathrm{mL})\end{array}$ & $1 \mathrm{~h}$ & $2 \mathrm{~h}$ & $3 \mathrm{~h}$ & $4 \mathrm{~h}$ & $5 \mathrm{~h}$ \\
\hline 250 & $40.0 \pm 0.0$ & $40.00 \pm 0.0$ & $28.33 \pm 0.88$ & $18.67 \pm 0.33$ & $10.33 \pm 0.33$ \\
500 & $40.00 \pm 0.0$ & $39.33 \pm 0.88$ & $24.33 \pm 0.58$ & $14.33 \pm 0.33$ & $6.667 \pm 0.33$ \\
750 & $40.00 \pm 0.0$ & $30.67 \pm 0.88$ & $14.67 \pm 0.33$ & $6.667 \pm 0.33$ & $0.0 \pm 0.0$ \\
1,000 & $38.33 \pm 0.33$ & $24.67 \pm 0.58$ & $9.333 \pm 0.33$ & $0.0 \pm 0.0$ & $0.0 \pm 0.0$ \\
$\begin{array}{l}\text { Diminazine aceturate (50) } \\
\text { (positive control) }\end{array}$ & $22.33 \pm 0.33$ & $9.000 \pm 0.58$ & $1.333 \pm 0.33$ & $0.0 \pm 0.0$ & $0.0 \pm 0.0$ \\
Control (negative control) & $40.00 \pm 0.0$ & $40.00 \pm 0.0$ & $40.00 \pm 0.0$ & $40.00 \pm 0.0$ & $40.00 \pm 0.0$ \\
\hline
\end{tabular}

Bioassay status: Significant reduction of parasites counts from concentration of $250 \mu \mathrm{g} / \mathrm{mL}$ and complete killing of parasites at $750 \mu \mathrm{g} / \mathrm{mL}$ at 5 th hour of observation. An average mean parasites count of $37.67 \pm 0.58$ is statistically critical value. Average mean parasites counts from $37.67 \pm 0.58$ and below is significant between the treatment groups and negative control $(P \leq 0.05$ to 0.01$)$. 
Table 7 Pooled Fractions IV (97 581).

\begin{tabular}{llllll}
\hline $\begin{array}{l}\text { Concentration of pooled plant } \\
\text { extract }(\mu \mathrm{g} / \mathrm{mL})\end{array}$ & $1 \mathrm{~h}$ & $2 \mathrm{~h}$ & $3 \mathrm{~h}$ & $4 \mathrm{~h}$ & $5 \mathrm{~h}$ \\
\hline 250 & $39.67 \pm 0.33$ & $20.00 \pm 0.0$ & $10.67 \pm 0.68$ & $4.667 \pm 0.33$ & $0.3333 \pm 0.33$ \\
500 & $38.67 \pm 0.68$ & $18.67 \pm 0.33$ & $9.000 \pm 0.0$ & $3.333 \pm 0.33$ & $0.0 \pm 0.0$ \\
750 & $36.33 \pm 0.68$ & $16.67 \pm 0.33$ & $7.667 \pm 0.33$ & $2.667 \pm 0.33$ & $0.0 \pm 0.0$ \\
1,000 & $33.33 \pm 0.33$ & $14.67 \pm 0.33$ & $0.0 \pm 0.0$ & $0.0 \pm 0.0$ & $0.0 \pm 0.0$ \\
$\begin{array}{l}\text { Diminazine Aceturate (50) } \\
\text { (positive control) }\end{array}$ & $22.33 \pm 0.33$ & $9.000 \pm 0.58$ & $1.333 \pm 0.33$ & $0.0 \pm 0.0$ & $0.0 \pm 0.0$ \\
Control (negative control) & $40.00 \pm 0.0$ & $40.00 \pm 0.0$ & $40.00 \pm 0.0$ & $40.00 \pm 0.0$ & $40.00 \pm 0.0$ \\
\hline
\end{tabular}

Bioassay status: Significant reduction of parasites counts from concentration of $250 \mu \mathrm{g} / \mathrm{mL}$ and complete killing of parasites at $500 \mu \mathrm{g} / \mathrm{mL}$ at 5 th hour of observation. An average mean parasites count of $37.67 \pm 0.58$ is statistically critical value. Average mean parasites counts from $37.67 \pm 0.58$ and below is significant between the treatment groups and negative control $(P \leq 0.05$ to 0.01$)$.

Table 8 In-vivo trypanocidal activity of methanolic extract of $E$. officinalis dried fruits in mice.

\begin{tabular}{|c|c|c|c|c|c|c|}
\hline $\begin{array}{l}\text { Concentration of test material in } \\
\mathrm{mg} / \mathrm{kg} \text { body weight }\end{array}$ & Day 2 & Day 3 & Day 4 & Day 5 & Day 6 & Day 7 \\
\hline 12.5 & $7.100 \pm 0.25$ & $26.67 \pm 0.88$ & $39.67 \pm 0.33$ & & & \\
\hline 25 & $8.667 \pm 0.33$ & $26.67 \pm 0.88$ & $38.00 \pm 0.59$ & & & \\
\hline 50 & $7.333 \pm 0.88$ & $23.00 \pm 0.68$ & $34.33 \pm 0.72$ & & & \\
\hline 100 & $6.667 \pm 0.33$ & $14.67 \pm 0.33$ & $22.33 \pm 0.33$ & $32.67 \pm 0.67$ & & \\
\hline 200 & $5.0000 \pm 0.58$ & $10.67 \pm 0.33$ & $19.00 \pm 0.58$ & $29.00 \pm 0.58$ & $39.67 \pm 0.33$ & $52.34 \pm 0.33$ \\
\hline $\begin{array}{l}\text { Diminazine Aceturate (10) } \\
\text { (positive control) }\end{array}$ & $6.167 \pm 0.3073$ & $0.0 \pm 0.0$ & $0.0 \pm 0.0$ & $0.0 \pm 0.0$ & $0.0 \pm 0.0$ & $0.0 \pm 0.0$ \\
\hline Control (negative control) & $6.167 \pm 0.31$ & $13.50 \pm 0.56$ & $39.50 \pm 0.43$ & & & \\
\hline
\end{tabular}

At dose rate of $200 \mathrm{mg} / \mathrm{kg}$ body weight, the mice in this group survived for 6 days post on set of parasitemia. There was significant difference $(P<0.05)$ between treated groups with test material in comparison to negative control that survived for only three days.

exhibited significant trypanocidal activity in all concentrations $(250 \sim 1,000 \mu \mathrm{g} / \mathrm{mL})$ with significant difference $(P<0.01)$.

\subsection{In-vivo Trypanocidal Activity of Methanolic Plant Extract of E. officinalis Dried Fruits}

In-vivo trypanocidal activity of MPE of E. officinalis dried fruits at different concentrations were given in Table 8. Mice in distinct groups treated with MPE of the test material at concentrations $(12.5,25,50,100$ and $200 \mathrm{mg} / \mathrm{mL}$ ) after the onset of parasitemia survived up to Days 4, 5 and 6, respectively, in comparison to Day 4 of untreated control with significant difference $(P<0.05)$.

\subsection{In-vivo Trypanocidal Activity of Partially} Purified Fractions of E. officinalis Dried Fruits in Mice

Partially purified fractions of E. officinalis fruits with high content of desired unidentified compounds with maximum in-vitro trypanocidal activity were used to treat parasitemic mice, which exhibited different levels of trypanocidal activity, were as given in Table 9 and Fig. 2. Mice treated with the obtained pooled fractions of bioactive constituents of interest survived for maximum 9 days post infection as to 4 days of untreated control with significant difference $(P \leq 0.05$ to 0.01$)$.

\subsection{HPLC (Higher Performance Liquid} Chromatography) Analysis of Pooled Fractions of E. officinalis Dried Fruits

HPLC analysis of representative pooled fractions of E. officinalis dried fruits that contained bioactive constituents of interest revealed two prominent peaks depicting more than one compounds at two detections (210 and $320 \mathrm{~nm}$ ), as given in Fig. 3. Detection at more than one wavelength depicted glaringly impurity of the 
Table 9 In-vivo trypanocidal activity of partially purified fractions of $E$. officinalis dried fruits in mice.

\begin{tabular}{|c|c|c|c|c|c|c|c|c|c|}
\hline $\begin{array}{l}\text { Concentration of test } \\
\text { materials }\end{array}$ & Day 2 & Day 3 & Day 4 & Day 5 & Day 6 & Day 7 & Day 8 & Day 9 & Day 10 \\
\hline 12.5 & $6.923 \pm 0.33$ & $14.33 \pm 0.33$ & $29.33 \pm 0.33$ & $42.67 \pm 0.67$ & & & & & \\
\hline 25 & $6.667 \pm 0.33$ & $13.00 \pm 0.58$ & $27.67 \pm 0.33$ & $41.00 \pm 0.58$ & & & & & \\
\hline 50 & $7.333 \pm 0.33$ & $12.00 \pm 0.58$ & $24.33 \pm 0.33$ & $37.00 \pm 0.58$ & $44.00 \pm 0.58$ & & & & \\
\hline 100 & $7.333 \pm 0.33$ & $11.33 \pm 0.33$ & $22.33 \pm 0.33$ & $20.00 \pm 1.0$ & $21.67 \pm 0.33$ & $26.33 \pm 0.33$ & $40.00 \pm 0.58$ & & \\
\hline 200 & $7.000 \pm 0.22$ & $9.333 \pm 0.33$ & $20.00 \pm 0.58$ & $17.67 \pm 0.58$ & $17.33 \pm 0.33$ & $17.00 \pm 0.58$ & $18.67 \pm 0.33$ & $29.00 \pm 0.58$ & $41.00 \pm 0.58$ \\
\hline $\begin{array}{l}\text { Diminazine aceturate } \\
\text { (10) (positive control) }\end{array}$ & $7.00 \pm 0.58$ & $0.33 \pm 0.33$ & $0.00 \pm 0.0$ & & & & & & \\
\hline $\begin{array}{l}\text { Control (negative } \\
\text { control) }\end{array}$ & $7.00 \pm 0.58$ & $22.33 \pm 0.45$ & $43.00 \pm 1.52$ & & & & & & \\
\hline
\end{tabular}

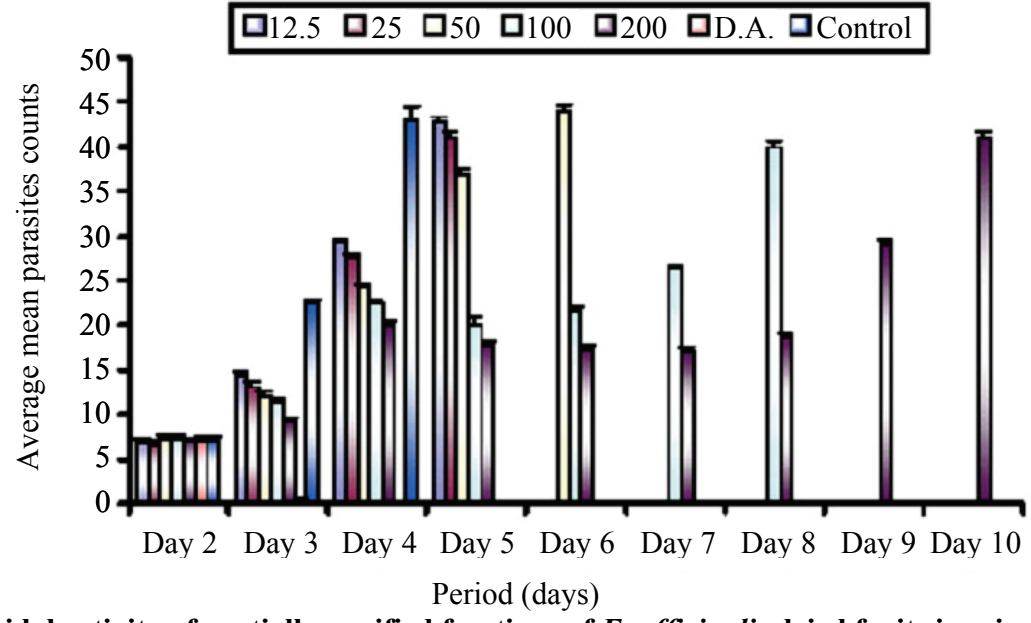

Fig. 2 In-vivo trypanocidal activity of partially purified fractions of $E$. officinalis dried fruits in mice.

Test extract: $250 \sim 1,000 \mu \mathrm{g} / \mathrm{mL}$;

DA: Diminazen Aceturate $(50 \mu \mathrm{g} / \mathrm{mL})$;

Control: parasites + medium.

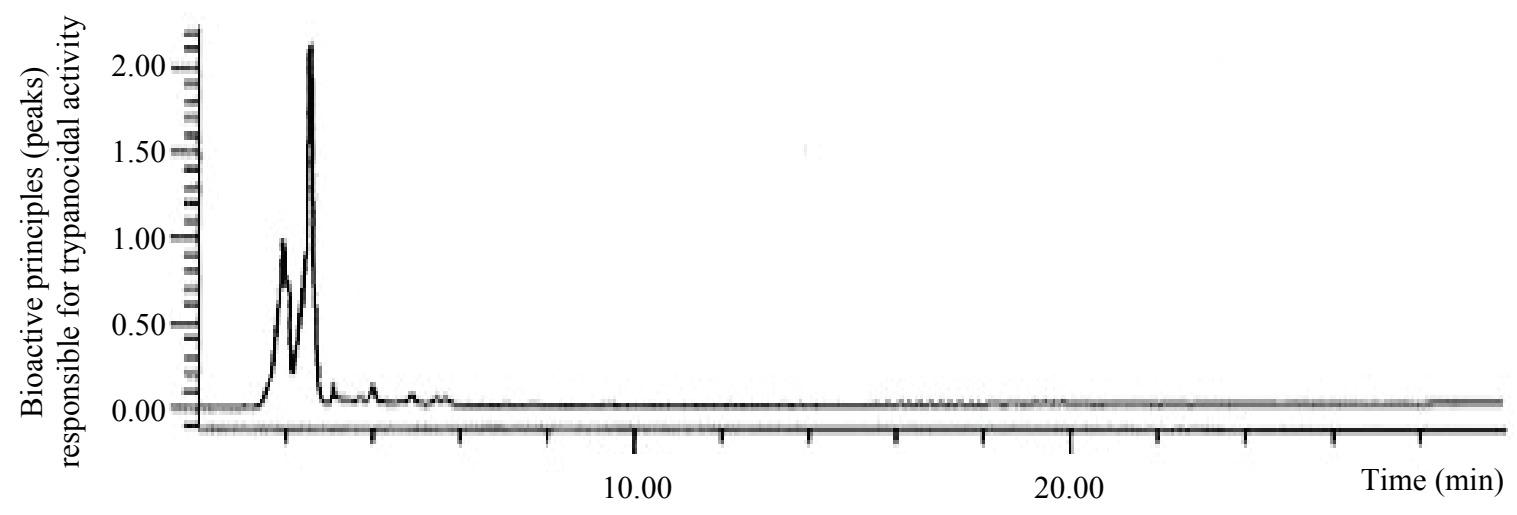

(a) 


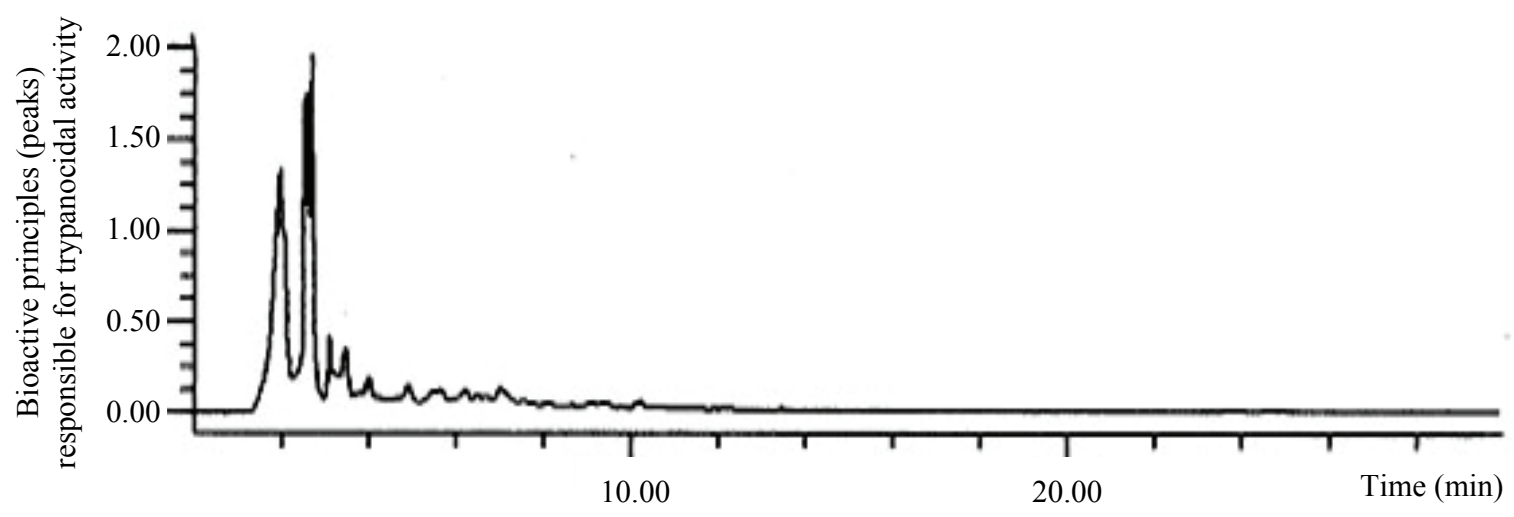

(b)

Fig. 3 HPLC profile of pooled fractions of column chromatography of $E$. officinalis: (a) detection: $210 \mathrm{~nm}$, flow rate: 1 $\mathrm{mL} / \mathrm{min}$; (b) injection: $20 \mu \mathrm{L}$, detection at: $320 \mathrm{~nm}$, flow rate: $1 \mathrm{~mL} / \mathrm{min}$.

representative pooled fractions of E. officinalis dried fruits.

\section{Discussion}

\subsection{Extraction}

In this report, methanol used in the extraction of $E$. officinalis dried fruits is similar to previous work documented by Shaba et al. [12, 30, 34].

\subsection{Solvent System}

Solvents, methanol and chloroform/ethyl acetate/acetic acid (50:50:1) used in analysis of TLC plates applied with MPE and fractions of E. officinalis dried fruits are comparable to that used in bioassay guided isolation of a diastereoisomer of kolavenol from Entada absyssinica [9].

\subsection{In-vivo Infectivity Test}

In-vivo infectivity test of MPE of the test is in line with work done by Igweh et al. [29] and Shaba et al. [35] where groups of mice inoculated with contents of ELISA plate wells with apparent killed trypanosomes survived.

\subsection{In-vitro Cytotoxicity Test}

Cytotoxic effects of E. officinalis dried fruits are comparable to cytotoxic effects of Terminalia arjuna bark extract with distortion and apoptosis of human hepatoma cell line (HEPG2) [36] and Terminalia belirica dried fruits with similar cytotoxic effects observed in this report [37].

\subsection{Acute Toxicity Test}

Acute toxicity test of MPE of the test material is comparable to that of Nuclea latifolia, in which no toxic sign was observed in rats at concentrations of $100 \sim 300 \mathrm{mg} / \mathrm{kg}$ body weight. But, fatalities were observed at 400 and $800 \mathrm{mg} / \mathrm{kg}$ body weight [32].

\subsection{Column Chromatography of Methanolic Extract of E. officials Dried Fruits}

Fractionation of MPE of E. officinalis dried fruits via column chromatography is similar to fractionation of Cannabis sativa with two fractions active against $T$. brucei rhodesiense [38, 39].

\subsection{In-vitro Trypanocidal Activity of Methanolic Extract of E. officinalis Dried Fruits}

This result is comparable to in vitro antitrypanosomal activity of some medicinal plants used in northern Nigeria against trypanosomosis with different level of antitrypanosomal activity at concentration of $8.3 \mathrm{mg} / \mathrm{mL}$ [40] and in-vitro screening of American plants extracts on Trypanosoma cruzi and Trichomonas vaginalis [41]. Trypanocidal activity, in this report, could be due to already isolated compounds, such as gallic acid from test material. Trypanocidal activity of gallic acid has been documented [42]. 


\subsection{In-vitro Trypanocidal Activity of PFs (Pooled Fractions) of E. officinalis Dried Fruits}

Results of varied trypanocidal activity of PFs of $E$. officinalis dried fruits is in line with that of fractionation of Cannabis sativa with two fractions active against $T$. brucei rhodesiense [39] and bioassay guided isolation of a diastereoisomer of kolavenol from Entada absyssinica active on Trypanosoma brucei rdesiense [9].

4.9 In-vivo Trypanocidal Activity of Methanolic Plant Extract of E. officinalis Dried Fruits in Mice

Distinct levels of in-vivo trypanocidal activity of MPE of test material is in line with trypanocidal activity of Nuclea latifolia in which treated mice exhibited decreased in parasitemia but could not cure the infected rat with trypanosomes [32] and in-vivo anti-trypanosomal activity of dichloromethane and methanol crude leaf extracts of Dovyalis abyssinica (Salicaceae) against Trypanosoma congolense with limited in-vivo result [43].

\subsection{Higher Performance Liquid Chromatography} Analysis of Pooled Fractions of E. officinalis Dried Fruits

HPLC analysis of pooled PPFs of E. officinalis dried fruit is comparable to fractionation and purification of bioassay guided isolation of a diastereoisomer of kolavenol from Entada absyssinica [9].

4.11 In-vivo Trypanocidal Activity of PPFs (Partially Purified Fractions) of E. officinalis Dried Fruits in Mice

In-vivo trypanocidal activity of PPFs of E. officinalis dried fruits is in line with fractionation of Cannabis sativa with two fractions active against $T$. brucei rhodesiense [39] and bioassay guided isolation of a diastereoisomer of kolavenol from Entada absyssinica active on Trypanosoma brucei rdesiense [9].

Mechanism of action of E. officinalis dried fruits may be due to gallic acid that has been isolated already from it and its corresponding trypanocidal activity has been documented [40]. Also, it could be due to intercalation of obtained extracts/fractions/isolated compounds of E. officinalis with the DNA of trypanosomes of which such actions have been reported [10].

Representative pooled fractions of PPFs of $E$. officinalis could not cure the mice but prolonged its lifespan to Day 9 post infection at maximum dose of $200 \mathrm{mg} / \mathrm{kg}$ body weight. This may be due to inability of the PPFs to sustain sufficient blood plasma to kill the trypanosomes and possibly, the ease of its being degraded in the body of the mice, which is common to such fractions/isolated compounds [10].

\section{Conclusions}

In conclusion, E. officinalis dried fruits exhibited significant in-vitro antitrypanosomal activity. Even though strong results of in-vitro trypanocidal activity was not completely transformed during in-vivo testing due to differences in physiological status, attained level bioassay-guided purification decreased cytotoxic effects level and increased trypanocidal activity as shown during in-vivo testing with PPFs of the test material. In near future, this could lead to development of urgently needed new trypanocide against menacing trypanosomes in both animals and humans.

Further purification of PPFs of E. officinalis dried fruits is needed to determine its maximum trypanocidal status.

\section{Acknowledgments}

India and Nigeria governments are highly acknowledged for the funding of this research work.

\section{References}

[1] Simarro, P. P., Franco, J. R., Cecchi, G., Paone, M., and Diarra, A. 2012. "Human African Trypanosomiasis in Non-endemic Countries (2000-2010)." Journal of Travel Medicine 19: 44-53.

[2] World Health Organization. 2012. Accelerating Work to Overcome Neglected Tropical Diseases: a Roadmap for Lmplementation. Geneva: World Health Organization. 


\section{Therapeutic Activity of Partially Purified Fractions of Emblica officinalis (Syn. Phyllanthus emblica) Dried Fruits against Trypanosoma evansi}

Accessed January 1, 2012. http://whqlibdoc.who.int/hq/ 2012/WHO_HTM_NTD_2012.1_eng.pdf.

[3] Abiodun, O. O., Gbotosho, G. O., Ajaiyeoba, E. O., Brun, R., and Oduola, A. M. 2012. "Antitrypanosomal Activity of Some Medicinal Plants from Nigerian Ethnomedicine." Parasitology Research 2: 521-6.

[4] World Health Organization. 2004. Communicable Disease Surveillance and Rsponse. Geneva: World Health Organization.

[5] World Health Organization. 2010. Working to Overcome the Global Impact of Neglected Tropical Diseases. First WHO report on neglected tropical diseases, No. 1, World Health Organization, Geneva.

[6] Seed, J. R. 2001. "African Trypanosomosis Research in 100 Years of Progress but Questions Remain." International Journal of Parasitologyl 31: 434-42.

[7] Hursey, B. S. 2000. "The Programme against African Trypanosomiasis.” Trends Parasitology 17: 99-100.

[8] Dou, F. and Yapo, F. B. 2001. "Uptake and Mode of Action of Drugs Used against Sleeping Sickness. 1-5 Years of Progress but Questions and Problems still Remains." Journal Biochemistry and Pharmacology 61: 25-28.

[9] Freiburghaus, F., Steck, A., Ptander, H., and Brun, R. 1998. "Bioassay Guided Lsolation of a Diastereoisomer of Kolavenol from Entada Absyssinica Active on Trypanosoma brucei rdesiense." Journal of Ethnopharmacology 61:179-83

[10] Nok, A. J., and Nock, C. 2002. "Transferin Coupled Azanthraquinone Enhances the Killing Effects on Trypanosomes. The Role of Mysosomal mannosidase." Journal of Patasites 9: 375-9

[11] Kubataa, B. K., Kisaburo, N., Nobutoshi, M., Patrick, M., Zakayi, K., Samuel, K., et al. 2005. "Kola acuminata proanthocyanidins: A Class of Anti-trypanosomal Compounds Effective against Trypanosoma brucei." International Journal of Parasitology 35: 91-103.

[12] Shaba, P., Pandey, N. N., Sharma, O. P., Rao, J. R., and Singh, R. K. 2009. "In-vitro Trypanocidal Activity of Comparative Extraction of Terminalia belirica Dried Fruits with Solvents of Different Polarities against Trypanosoma evansi." Internet Journal Veterinary Medicine 6 (1): 1-5.

[13] Shaba, P., Pandey, N. N., and Singh, R. K. 2014. "Evaluation of Antitrypanosomal Activity of Methanolic Extracts of Moringa oleifera Lam Tree Bark and Seed Pods." Researh Journal of Engineering and Apply Sciences 3: 43-9.

[14] Shaba, P., Dey, S., Kurade, N. P., and Singh, R. K. 2016. "Antitripanosomal Activity of Picrorrhiza kurroa Rhizomes against Trypanosoma evansi." Advances in Pharmacognosy and Phytomedicine 1 (1): 49-54.
[15] Maurya, U., and Srivastava, S. 2011. "Traditional Indian Herbal Medicine Used as Antipyretic, Antiulcer, Anti-diabetic and Anticancer: A Review." International Journal of Research in Pharmaceutical Chemistry 1 (4): 1152-9.

[16] Srivasuki, K. P. 2012. "Nutritional and Health Care Benefits of Amla." Journal of Pharmacognosy 3 (2): 141-51.

[17] Zhang, L. Z., Zhao, W. H., Guo, Y. J., Tu, G. Z., Lin, S., and Xin, L. G. 2003. "Studies on Chemical Constituents in Fruits of Tibetan Medicine Phyllanthus emblica." Zhongguo Zhong Yao Za Zhi 28 (10): 940-3.

[18] Udupa, K. N. 1985. "Ayurveda for Promotion of Health." Journal of Ayurveda, Vol. 3.

[19] Nosal Ova, G., Mokry, J., and Hasan, K. M. 2003. "Antitussive Activity of the Fruit Extract of Emblica officinalis Gaertn, (Euphorbiaceae)." Phytomedicine 10: 583-9.

[20] El-Desouky, S. K., Ryu, S. Y., and Kim, Y. K. 2008. “A New Cytotoxic Acylatedapigeninglucoside from Phyllanthus emblica L." Natural Product Research 22 (1): 91-5.

[21] Sharma, S. K., James, B., Perianayagam, A., Joseph, A. J. M., and Christina, A. 2004. "Evaluation of Anti-pyretic and Analgesic Activity of Emblica officinalis Gaertn." Journal of Ethnopharmacology 95: 83-5.

[22] Rehman, H., Yasin, K. A., Choudhary, M. A., Khaliq, N., Rahman, A., Choudhary, M. I., et al. 2007. "Studies on the Chemical Constituents of Phyllanthus emblica." Natural Product Research 21 (9): 775-81.

[23] Shaba, P., Pandey, N. N., Sharma, O. P., Rao, J. R., and Singh, R. K. 2012. "Anti-trypanosomal Activity of Piper nigrum L (Black Pepper) against Trypanosoma evansi." Journal of Veterinary Advances 2: 161-7.

[24] Stahl, E. 1969. Thin Layer Chromatography: A Laboratory Handbook. New York: Springer.

[25] Williamson, J., March, J. C., and Scott-Finning, J. J. 1982. "Drug Synergy in Experimental African Trypanosomiasis." Tropennmedizin und Parasitologie 33: 76-82.

[26] Oliveira, B. A., Pereira, D. G., Fernandes, A. M. A. P., DeCastro, S. L., Souza, A. R. M., and Brito, A. O., and Duran, N. 2004. "Trypanocidal Activity of 2-propen-1-amine Derivatives on Trypomastigotes Culture and in Animal Model." Journal of Parasitology Research 9: 1125.

[27] Talakal, T. S., Dwivedi, S. K. and Sharma, P. 1995. "In-vitro and in-vivo Antitrypanosomal Activity of Xanthium strumarium Leaves." Journal of Ethnpharmacology 49: 141-5.

[28] Young, V., Schmitz, V., Vanner-Santos, M. A., Lima, A. P. C. A., Lalmanach, G., Juliano, L., et al. 2000. "Altered 
Expression of Cruzipain and a Cathepsin B-Like Target in a Trypanosoma cruzi Cell Line Displaying Resistance to Synthetic Inhibitors of Cysteine-Proteinases.” Journal Molecular Biochemistry and Parasitolology 109: 47-59.

[29] Igweh, A. C., Aguiyi, J. C., and Okwuaasaba, F. K. 2002. "Antitrypanosomal Affect of the Aqueous Extract of Brassisca oleracea." Journal of Fitoterapia 71: 17-21.

[30] Shaba, P., Pandey, N. N., Sharma, O. P., Rao, J. R., and Singh, R. K. 2007. "In-vitro Trypanocidal Activity of Picrorrhiza kurroa Rhizomes against Trypanosoma evansi." Planta Medica 73: 997-1034.

[31] Sidwell , R. W., and Huffman, J. H. 1997. “Antiviral Drug Resistance.” Research Virology 148: 353-65.

[32] Madubunyi, L. 1995. "Antihepatotoxic and Trypanocidal Activity of Nuclear latifolia Bark Root.” Journal of Herps, Spices and Medicinal Plants 3: 33-5.

[33] Sharma, O. P., Anita, S., and Sarita, S. 2000. "Pentacylic Lantadenes Triterpenoids in Young and Mature Leaves of Lantana camara var Aculeate." Fitoterapia 71: 487-91.

[34] Shaba, P., Pandey, N. N., Sharma, O. P., Rao, J. R., Singh, R. K. 2006. "Antitrypanosomal and Cytotoxicity of Methanolic Plumbago zeylanica Root Bark against Trypanosoma evensi." Journal of Veterinary Public Health 4: 31-6.

[35] Shaba, P., Dey, S., Mandal, B. D., Singh, R. K., and Chaudary, P. 2016. "Trypanocidal Activity of 50\% Methanolic Extract of Khaya senegalensis Tree Bark." Advances in Pharmacognosy and Phytomedicine 2 (1): 9-14.

[36] Sarveswaran, S., Marati, R. V., and Marathaiveeran, P.B. 2006. "Effects of Terminalia arjuna Bark Extract on Opoptosis of Human Hepatoma Cell line (HEPG2)."
Indian Journal of Gastrology 12: 1015-24.

[37] Shaba, P., Pandey, N. N., Sharma, O. P., Rao, J. R., and Singh, R. K. 2008. "In-vitro Trypanocidal and Cytotoxicity Effects of Methanolic Extract of Vitex negundo Leaves against Trypanosoma evansi." Presented at the 13th Congress of the Federation of Asian Veterinary Associations, FAVA-OIE Joint Symposium on Emerging Diseases, Bangkok, Thailand.

[38] Bruneton, J. 1995. Pharmacognosyand Phytochemistry of Medicinal Plants. Paris: Laviosier Publishing, 333-9.

[39] Nok, A. J., Salisi, I., Arowosafe, S., and Whong, C. Z. 1995. "The Trypanocidal Effect of Cannabis sativa Constituents in Experimental Animal Trypanosomiasis." Veterinary and Human Toxicology 36 (6): 522-4.

[40] Wurochekke, A. U., and Nok, A. J. 2004. "In-vitro Anti-trypanosomal Activity of Some Medicinal Plants Used in the Treatment of Trypanosomosis in Northern Nigeria." Africa Journal of Biotechnology 3: 481-3.

[41] Muella-Serrano, S., Nogal, J. J., Martinez-Diaz, R. A., Escario, J. A., and Gomez Barrio, A. 2000. "In-vitro Screening of American Plants Extracts on Trypanosoma cruzi and Trichomonas vaginalis." Journal of Ethnopharmacology Limerick 71: 101-7.

[42] Koide, T., Nose, M., Ogihara, T., Yabo, Y., and Ohta, M. 1998. "Trypanocidal Effect of Gallic Acid and Related Compounds." Journal of Planta Medica 61: 27-30.

[43] Belay, T., Getachew, T., Nigatu, K., and Workineh, S. 2015. "In-vivo Anti-trypanosomal Activity of Dichloromethane and Methanol Crude Leaf Extracts of Dovyalis abyssinica (Salicaceae) against Trypanosoma congolense." BMC Complement and Alternative Medicine 15: 278-89. 